\title{
Prevalence and degrees of myopia and hyperopia at Gondar University Hospital Tertiary Eye Care and Training Center, Northwest Ethiopia
}

This article was published in the following Dove Press journal:

Clinical Optometry

21 November 2016

Number of times this article has been viewed

\section{Destaye Shiferaw Alemu \\ Alemayehu Desalegn \\ Gudeta \\ Ayanaw Tsega Ferede \\ Haile Woretaw Alemu}

Department of Optometry, College of Medicine and Health Sciences, Gondar University, Gondar, Ethiopia
Correspondence: Destaye Shiferaw Alemu

Department of Optometry, College of Medicine and Health Sciences, Gondar University, PO Box 196,

Gondar, Ethiopia

Tel +25I 9180322

Email destayest@gmail.com
Background: Refractive errors are the second and third leading cause of visual impairment and blindness in Ethiopia, respectively. The situation is worse where accessing spectacles, which are the only management option in developing countries, is a major issue. Gondar University Hospital Tertiary Eye Care and Training Center is the only referral eye care center, and it lacks published evidence on the prevalence and degrees of refractive errors (myopia and hyperopia). Objective: The purpose of this study was to determine the prevalence and degrees of myopia and hyperopia at Gondar University Tertiary Eye Care and Training Center.

Materials and methods: Records of 1,921 patients presented to refraction service at Gondar University Hospital Tertiary Eye Care and Training Center from January 2010 to January 2014 were reviewed. All cases of refractive errors (with visual improvement of at least one line) were converted into spherical equivalents $(\mathrm{SE}=$ sphere $+1 / 2$ cylinder). Myopia was defined as $\mathrm{SE} \leq$ $-0.25 \mathrm{D}$ and hyperopia $\geq+0.25 \mathrm{D}$.

Results: The study comprised of $61.1 \%$ males and $38.9 \%$ females; the patients had an average age of $40 \pm 17$ years. The overall prevalence of refractive errors (myopia and hyperopia) was $76.3 \%$ (95\% confidence interval: $75 \%-77 \%$ ). Myopia was present in $34.5 \%$ patients and hyperopia in $38.3 \%$. Low-degree hyperopia (86\%) and low-degree myopia (49.5\%) were the most frequent refractive errors.

Conclusion: Myopia and hyperopia are major reasons for patients to visit Gondar University Hospital Tertiary Eye Care and Training Center. Low-degree myopia and hyperopia were the most common refractive errors. Stocking appropriate power lenses is needed at this tertiary eye care center in order to alleviate this problem in Ethiopia.

Keywords: degree of myopia, hyperopia, Gondar, Ethiopia

\section{Introduction}

Uncorrected refractive error has been recognized as a major public health problem because of the high rates of low vision and blindness it causes compounded by the poor accessibility of spectacles. ${ }^{1,2}$

Globally, it is estimated that more than 2.3 billion people suffer from poor vision due to uncorrected refractive error. ${ }^{1}$ Among people having refractive errors, only 1.8 billion have access to adequate eye examination and affordable corrections, leaving behind 500 million people, mostly in developing countries. ${ }^{3}$ In 2007, 158.1 million cases of visual impairment resulted from uncorrected or undercorrected refractive error, of whom 8.7 million were blind. ${ }^{4}$

Uncorrected refractive error has social, psychological, and economic impacts on individuals and communities at large. ${ }^{4-8}$ In the last few years, due attention has been 
given to the contribution of refractive errors as a global cause of visual impairment and blindness. This is because of the realization that burden of refractive errors based on best-corrected visual acuity underestimated the contribution of refractive errors. ${ }^{5}$

International organizations including the global initiative for the Elimination of Avoidable Blindness are working relentlessly to avoid the impacts of preventable blindness, which of course requires both governments and private sectors commitment to allocate more budget to improve the provision and uptake of eye care services. ${ }^{9-11}$

In addition, effective management of visual impairment caused by refractive errors requires the establishment of proper service structures to match the magnitude of the problem. ${ }^{1}$ The lack of affordable refractive correction measures such as availability of spectacles in poor countries is one of the primary reasons for the millions of people across the globe suffering from poor vision. ${ }^{4}$ It is time to develop and implement efficient, effective, and sustainable service delivery models for the correction of visual impairment due to uncorrected refractive errors.

Refractive error is correctable with eyeglasses, contact lenses, or laser surgery. However, spectacles are the most cost-effective corrective interventions, especially in countries where other options are scarce. ${ }^{8,12}$

There is a visible disconnection between eye care and refractive services, especially in accessing the appropriate power for the specific refractive error. For example, because of lack of appropriate lens power prescribed for patients presented to hospitals, they are only given a prescription and are forced to purchase spectacles from the private sector, ${ }^{13}$ which is likely to be costly.

In Ethiopia, refractive errors account for $33.4 \%$ of the causes of low vision and $7.7 \%$ of blindness (followed by cataract, $49.9 \%$, and trachomatous corneal opacity $11.5 \%) .{ }^{14}$ Yet, there is no published evidence on the magnitude and degree of refractive errors.

The purpose of this study was to determine the prevalence and degrees of myopia and hyperopia. The findings from the study help for appropriate planning and stocking of most demanded lenses.

\section{Materials and methods Study design and setting}

A hospital-based descriptive cross-sectional study was carried out on the records of patients who visited Gondar University Tertiary Eye Care and Training Center from 2010 to 2014. Gondar University Tertiary Eye Care and Training Center is situated in Gondar town, Northwest Ethiopia, $730 \mathrm{~km}$ from the capital, Addis Ababa. The eye care center is the major public facility providing eye care services for the population within and around the catchment treating an approximate 14 million people. The eye care center provides different specialty eye care services and training for ophthalmology and optometry. The specialty areas in the eye care center include major and minor operation theater, general outpatient departments, refraction service with optical workshop where lenses are fit, and glaucoma, pediatric, anterior segment, and retinal clinics.

\section{Source and study population}

The source population was all patients who had visited the refraction clinic of Gondar University Hospital Tertiary Eye Care and Training Center from 2010 to 2014. All the records were retrieved for review, and those records with complete information for the purpose of the study were included for analysis.

\section{Inclusion and exclusion}

All patients who visited the refraction clinic for refraction (or those suspected for refractive error) were included in the study, except in cases where lenses did not improve vision (at least one line) or where details of the refractive findings were not recorded. All records with complete information on subjective refraction result were included. Patients with refractive errors not corrected with spectacles were excluded from the study.

\section{Definitions used for the study}

Refractive errors were considered based on the spherical equivalent (SE) as follows: "myopia" of $\mathrm{SE} \leq-0.25 \mathrm{D}$; "hyperopia" of $\mathrm{SE} \geq+0.25 \mathrm{D}$, low myopia (<-3.00 D), moderate myopia (SE -3.00 to $-6.00 \mathrm{D}$ ), high myopia (SE $<-6.00 \mathrm{D}$ ), low hyperopia $\mathrm{SE} \geq+0.25$ to $+2.75 \mathrm{D}$, moderate hyperopia $\mathrm{SE}+3.00$ to $+5.00 \mathrm{D}$, and high hyperopia > +5.00 D. Subjects aged 16 years or younger were considered as children and those older than 16 years were considered adults. The subjective refraction result for both eyes was collected and changed into its SE by using the formula: $\mathrm{SE}=$ sphere $+1 / 2$ cylinder.

\section{Data collection tools and methods}

Records of 1,921 patients were reviewed by practicing optometrists using a standardized checklist. SE for the subjective refraction for each eye was calculated. All spherical results with an SE of \pm 0.25 or more were included for analysis. Myopia and hyperopia were classified into high, medium, and low degree for right and left eye after the SE was 
obtained. Those SEs with a "plano value" were considered as "emmetropia." Data quality was ensured via training of data collectors, supervision, and cross checking of $5 \%$ of the records by the principal investigator.

\section{Data management and analysis}

The Statistical Package for Social Sciences version 16.0 software (SPSS Inc., Chicago, IL, USA) for Windows was used to enter and analyze data. The refractive data from each eye were used separately for analysis. Chi-square and independent $t$-tests were applied for categorical and continuous comparison tests as appropriate. $p<0.05$ with $95 \%$ confidence intervals (CIs) were considered statistically significant.

\section{Ethical considerations}

Ethical clearance was obtained from the research committee of Gondar University Hospital Tertiary Eye Care and Training Center. Permission was obtained from the hospital chief executive office to retrieve patient records. Medical confidentiality was assured by keeping data with password protection in a computer that was used only by the principal investigator. Demographic data such as age and sex of patients were collected in a standardized data compilation format. Written informed consent was deemed not necessary by the research committee of Gondar University Hospital Tertiary Eye Care and Training Center due to the retrospective nature of this study.

\section{Results}

\section{Sociodemographic characteristics of the study population}

A total of 1,921 records were included in the analysis. One thousand and one hundred seventy three $(61.9 \%)$ patients were males and $748(38.9 \%)$ were females. The male to female ratio was 1.6:1. The mean age of the study population was $40 \pm 17$ years. The average age of males and females was $41 \pm 17$ years and $37 \pm 16$ years, respectively, which was not statistically significant $(p<0.001)$. One hundred ten of the patients were $\leq 16$ years of age.

\section{Overall prevalence of refractive errors}

The overall prevalence of refractive errors was $76.3 \%$ (95\% CI: $75 \%-77 \%$ ). The prevalence of either myopia or hyperopia in the right and left eye was $72.7 \%(1,397)$ and $72.6 \%(1,395)$, respectively. Among 1,921 study subjects, the prevalence of refractive error in males and females was $45.8 \%$ (879) and $30.5 \%$ (586), respectively. Of the cases with refractive error $(\mathrm{n}=1,465), 879(60.0 \%)$ were males and $586(40.0 \%)$ were females (Table 1). However, this difference in refractive status
Table I Sociodemographic characteristics of study population at Gondar University Hospital Tertiary Eye Care and Training Center, Northwest Ethiopia, $2014(n=1,921)$

\begin{tabular}{lll}
\hline Characteristics & Frequency & Percent \\
\hline Sex & & \\
Male & 1,173 & 61.1 \\
Female & 748 & 38.9 \\
Age (years) & & \\
I-10 & 22 & 1.1 \\
II-20 & 304 & 15.8 \\
$2 I-30$ & 349 & 18.2 \\
$31-40$ & 298 & 15.5 \\
$4 I-50$ & 473 & 24.6 \\
$5 I-60$ & 282 & 14.7 \\
$6 I-70$ & 116 & 6.1 \\
$7 I-80$ & 66 & 3.4 \\
$8 I+$ & 11 & 0.6 \\
Age category & & \\
Children & 110 & 5.7 \\
Adults & 1,811 & 94.3 \\
\hline
\end{tabular}

Table 2 Myopia and hyperopia distribution at Gondar University Hospital Tertiary Eye Care and Training Center, Northwest Ethiopia, $2014(n=I, 465)$

\begin{tabular}{lll}
\hline Characteristics & \multicolumn{2}{c}{ Refractive error (myopia and hyperopia) } \\
\cline { 2 - 3 } & Number & Percent \\
\hline Sex & 879 & \\
Male & 586 & 60.0 \\
Female & & 40.0 \\
Age group (years) & 21 & \\
I-10 & 284 & 1.4 \\
II-20 & 303 & 19.4 \\
2I-30 & 187 & 20.7 \\
3I-40 & 293 & 12.8 \\
$4 I-50$ & 223 & 20.0 \\
$5 I-60$ & 91 & 15.2 \\
6I-70 & 53 & 6.2 \\
7I-80 & 10 & 3.6 \\
$8 I+$ & & 0.7 \\
Age category & 106 & 7.2 \\
Children & 1,359 & 92.8 \\
Adult &
\end{tabular}

was independent of sex $\left(\chi^{2}=2.9, p=0.08\right)$, but dependent on the age of the subjects $\left(\chi^{2}=2.9, p<0.001\right)$.

\section{Prevalence and distribution of hyperopia and myopia}

Hyperopia was present in 735 right eyes, representing 38.3\% (95\% CI: 37\%-40\%) of those with refractive error and in 729 left eyes, representing 37.9\% (95\% CI: 36\%-40\%). Similarly, myopia was present in 664 right eyes, representing 34.6\% (95\% CI: 33\%-36\%) and in 663 left eyes, representing 34.5\% (95\% CI: $33 \%-36 \%$ ) of the refractive errors.

Hyperopia in the right eye was present in 58.8\% (432) and $41.2 \%$ (303) males and females, respectively, while 
myopia was present in 61.6\% (409) and 38.4 (255) males and females, respectively. However, both of these differences were not statistically significant $(p>0.05)$.

The mean hyperopic SE in the right eye (735) was $1.86 \pm 1.98$ $\mathrm{D}$, ranging from +0.25 to $+14.00 \mathrm{D}$. The mean SE for males $(n=432)$ was $1.94 \pm 2.07 \mathrm{D}$, ranging from +0.25 to $+14.00 \mathrm{D}$, while it was $1.74 \pm 1.84 \mathrm{D}$ in females $(\mathrm{n}=303)$, with a minimum and maximum of +0.25 to $+11.00 \mathrm{D}$, respectively. However, it was not statistically significant $(t=1.35, d f=733, p=0.177)$. The refractive power ranged from +0.25 to $+14.25 \mathrm{D}$ in the right eye and from +0.25 to $+18.00 \mathrm{D}$ in the left (Table 3 ).

The mean myopic SE in the right eye $(n=662)$ was $-4.91 \pm 4.87 \mathrm{D}$, with a minimum and maximum of -0.25 and $-26.00 \mathrm{D}$, respectively. The mean myopic SE in the right eye in males $(n=407)$ was $-4.66 \pm 4.86 \mathrm{D}$, with a range of -0.25 to $-22.00 \mathrm{D}$, while it was $-5.31 \pm 4.86 \mathrm{D}$ in females $(\mathrm{n}=255)$, with a minimum and maximum of -0.25 to $-26.00 \mathrm{D}$, respectively. However, this difference was not statistically significant ( $t=1.67, d f=660, p=0.095$ ). The hyperopic and myopic mean $\mathrm{SE}$ in the left eye was $+1.82 \pm 1.99 \mathrm{D}$, ranging from +0.25 to $+18.00 \mathrm{D}$ and $-4.77 \pm 4.85 \mathrm{D}$, respectively.

The distribution of hyperopic SE for males in the left eye was right skewed with a median of $+1.25 \mathrm{D}$ (interquartile range $[\mathrm{IQR}]$ of $+0.75-2.25 \mathrm{D})$. The mean myopic $\mathrm{SE}$ refrac-

Table 3 Hyperopia in the right and left eye based on SE at Gondar University Hospital Tertiary Eye Care and Training Center, Northwest Ethiopia, 2014

\begin{tabular}{|c|c|c|c|c|}
\hline \multirow[t]{2}{*}{ Range (D) } & \multicolumn{2}{|c|}{ Right eye $(n=735)$} & \multicolumn{2}{|c|}{ Left eye $(n=729)$} \\
\hline & Number & Percent & Number & Percent \\
\hline+0.25 to +0.75 & 230 & 31.3 & 229 & 31.4 \\
\hline+1.00 to +1.50 & 220 & 29.9 & 221 & 30.4 \\
\hline+1.75 to +2.25 & 117 & 15.9 & 132 & 18.1 \\
\hline+2.50 to +3.00 & 78 & 10.7 & 59 & 8.1 \\
\hline+3.25 to +3.75 & 23 & 3.1 & 25 & 3.5 \\
\hline+4.00 to +4.50 & 18 & 2.4 & 18 & 2.5 \\
\hline+4.75 to +5.25 & 14 & 1.9 & 6 & 0.8 \\
\hline+5.50 to +6.00 & 7 & I.I & 9 & 1.4 \\
\hline+6.50 to +7.00 & 2 & 0.4 & 2 & 0.3 \\
\hline+7.50 to +8.00 & I & 0.1 & 9 & 1.2 \\
\hline+8.50 to +9.00 & 6 & 0.8 & 5 & 0.6 \\
\hline+9.50 to 10.00 & 4 & 0.5 & 4 & 0.5 \\
\hline+10.50 to +11.00 & 5 & 0.6 & 5 & 0.6 \\
\hline+11.50 to 12.00 & 6 & 0.8 & 4 & 0.5 \\
\hline+12.50 to +13.00 & 3 & 0.4 & 0 & 0.0 \\
\hline+13.50 to +14.00 & I & 0.1 & 0 & 0.0 \\
\hline+14.50 to +15.00 & 0 & 0.0 & 0 & 0.0 \\
\hline+16.00 to +17.50 & 0 & 0.0 & 0 & 0.0 \\
\hline+18.00 to +18.50 & 0 & 0.0 & 1 & 0.1 \\
\hline
\end{tabular}

Abbreviation: SE, spherical equivalent. tive error in the left eye for males $(n=404)$ was left skewed with a median of $-2.75 \mathrm{D}$ (IQR of -6.00 to $-1.00 \mathrm{D}$ ).

The most frequent myopic refractive error was in the range -0.25 to $-0.75 \mathrm{D}$, and the least frequent observed refractive error in the right eye was in the range of -17.50 to $-18.00 \mathrm{D}$. The distribution of hyperopia for females' left eye was right skewed with a median of $1.25 \mathrm{D}$ (IQR of +0.75 to $+2.00 \mathrm{D})$, and the distribution of myopia was left skewed with a median of $-3.00 \mathrm{D}$ (IQR of -1.00 to $-8.00 \mathrm{D})$. The refractive power ranged from -0.25 to $-26.00 \mathrm{D}$ and from -0.25 to $-17.50 \mathrm{D}$ in the right and left eyes, respectively (Table 4).

\section{Degrees of hyperopia and myopia}

Low-degree hyperopia was the most frequently observed $(86 \%)$ type of refractive error, while high-degree hyperopia was observed the least $(4.5 \%)$. Of the $72.6 \%$ patients with refractive error in the left eye, $34.5 \%$ and $37.9 \%$ had myopia and hyperopia, respectively. Low-degree myopia accounted for $49.5 \%$, followed by high-degree myopia (26.8\%) and moderate-degree myopia (23.7\%). The most frequently observed hyperopia was low-degree hyperopia, accounting

Table 4 Ranges of myopic refractive errors in the right and left eye at Gondar University Hospital Tertiary Eye Care and Training Center, Northwest Ethiopia, 2014

\begin{tabular}{|c|c|c|c|c|}
\hline \multirow[t]{2}{*}{ Range (D) } & \multicolumn{2}{|c|}{ Right eye $(n=662)$} & \multicolumn{2}{|c|}{ Left eye $(n=663)$} \\
\hline & Number & Percent & Number & Percent \\
\hline-0.25 to -0.75 & 102 & 15.4 & 120 & 18.1 \\
\hline-1.00 to -1.50 & 118 & 17.8 & 106 & 16.0 \\
\hline-1.75 to -2.25 & 76 & 11.5 & 70 & 10.6 \\
\hline-2.50 to -3.00 & 39 & 5.9 & 56 & 8.4 \\
\hline-3.25 to -3.75 & 33 & 5.0 & 30 & 4.5 \\
\hline-4.00 to -4.50 & 46 & 6.9 & 51 & 7.7 \\
\hline-4.75 to -5.25 & 32 & 4.8 & 27 & 4.0 \\
\hline-5.50 to -6.00 & 35 & 5.3 & 25 & 3.8 \\
\hline-6.25 to -6.75 & 9 & 1.4 & 7 & 1.0 \\
\hline-7.00 to -7.50 & 17 & 2.6 & 22 & 3.3 \\
\hline-7.75 to -8.25 & 14 & 2.1 & 16 & 2.4 \\
\hline-8.50 to -9.00 & 20 & 3.0 & 5 & 0.8 \\
\hline-9.25 to -9.75 & 4 & 0.6 & 17 & 2.6 \\
\hline-10.00 to -10.50 & 21 & 3.2 & 14 & 2.0 \\
\hline-10.75 to -11.25 & 21 & 3.2 & 19 & 2.9 \\
\hline-11.50 to -12.00 & 6 & 0.9 & 9 & 1.4 \\
\hline-12.25 to -12.75 & 10 & 1.5 & 8 & 1.2 \\
\hline-13.00 to -13.50 & 7 & 1.1 & 13 & 1.9 \\
\hline-13.75 to -14.25 & 8 & 1.2 & 4 & 0.6 \\
\hline-14.50 to -15.00 & 4 & 0.6 & 5 & 0.8 \\
\hline-15.25 to -15.75 & 5 & 0.8 & 3 & 0.5 \\
\hline-16.00 to -16.50 & 13 & 2.0 & 15 & 2.3 \\
\hline-16.75 to -17.25 & 8 & I.I & 5 & 0.8 \\
\hline-17.50 to -18.00 & 1 & 0.1 & 16 & 2.4 \\
\hline$\geq-18.25$ & 13 & 2.0 & 0 & 0.0 \\
\hline
\end{tabular}


Table 5 Degrees and types of refractive errors in the left and right eye based on SE at Gondar University Hospital Tertiary Eye Care and Training Center, Northwest Ethiopia, 2014

\begin{tabular}{|c|c|c|c|c|c|c|c|c|}
\hline \multirow{3}{*}{$\begin{array}{l}\text { Degree } \\
\text { of RE }\end{array}$} & \multicolumn{4}{|c|}{ Right eye } & \multicolumn{4}{|c|}{ Left eye } \\
\hline & \multicolumn{2}{|c|}{$\begin{array}{l}\text { Hyperopia } \\
(n=735)\end{array}$} & \multicolumn{2}{|c|}{$\begin{array}{l}\text { Myopia } \\
(n=662)\end{array}$} & \multicolumn{2}{|c|}{$\begin{array}{l}\text { Hyperopia } \\
(n=729)\end{array}$} & \multicolumn{2}{|c|}{$\begin{array}{l}\text { Myopia } \\
(n=663)\end{array}$} \\
\hline & $\overline{\mathbf{N}}$ & $\%$ & $\mathbf{N}$ & $\%$ & $\mathbf{N}$ & $\%$ & $\mathbf{N}$ & $\%$ \\
\hline Low & 632 & 86.0 & 316 & 47.7 & 634 & 87.0 & 328 & 49.5 \\
\hline Moderate & 70 & 9.5 & 165 & 25.0 & 58 & 8.0 & 157 & 23.7 \\
\hline High & 33 & 4.5 & 181 & 27.3 & 37 & 5.0 & 178 & 26.8 \\
\hline
\end{tabular}

Abbreviations: $\mathrm{N}$, number; $\mathrm{RE}$, refractive error; $\mathrm{SE}$, spherical equivalent.

for $87 \%(\mathrm{n}=634)$, followed by moderate-degree hyperopia $8 \%(n=58)$ and high-degree hyperopia $5 \%(n=37$; Table 5$)$.

\section{Discussion}

This study tried to determine the prevalence and degrees of refractive errors (myopia and hyperopia) at a Tertiary Eye Care and Training Center in Northwest Ethiopia. To the best of the authors' knowledge, there is no documented evidence on the prevalence and degrees of refractive error at the only referral Tertiary Eye Care Center in Northwest Ethiopia. This study, therefore, provided a preliminary report on the magnitude and degrees of refractive error, which helps to improve the availability of most demanded lenses for refractive error correction.

\section{Limitations}

Readers of this paper need to be cautious about the certain limitations of the study. Being a hospital-based record review study, it has the inherent limitations of secondary data. These include, but are not limited to, selection bias, poor recording system, incomplete data, and inconsistencies, limiting the generalizability of the findings to the population at large. The selection bias results from the fact that only those with a complete record of cases were included for analysis. The other important limitation of this study was that astigmatism, which affects visual acuity more significantly than spherical refractive error, was not considered in the analysis. Furthermore, in this study, SEs were used to identify refractive errors for analysis. As a result SEs with plano value were considered as "emmetropia." This might result in the underestimation of the result. Notwithstanding the aforementioned limitations, the results of this study can be used for planning refractive error services including stocking lenses with the appropriate power and stocking the most demanded lenses.

Different studies on refractive errors across the globe differ in the method they use, the definition of refractive errors, the study population, the way refraction is assessed (wet versus dry refraction), the cutoff point to consider for refractive error, study setting, data analysis, and classifying refractive errors into significant and nonsignificant based on the cutoff point. These make comparing the findings of this study with previous studies difficult. Nevertheless, it is important to make relative comparisons in magnitude regardless of the aforementioned cross-cut issues so as to bring the importance of refractive errors for proper resource allocation in refractive error intervention in Ethiopia.

In this study, refractive error was observed in $76.3 \%$ (95\% CI: $75 \%-77 \%$ ) of the patients, which is higher compared with findings from Greece $(57.0 \%),{ }^{3}$ Nigeria $(54.3 \%),{ }^{13}$ and Ethiopia (33.4\%). ${ }^{14}$ This variation may be accounted by the method used, the way refractive error was measured, the population targeted for the study, and the cutoff point for refractive errors considered. For example, in the Ethiopian study, the study was community based with only pinhole improvement, which undermines high myopia prevalence. Although the studies in Greece and Nigeria were similar in study setting to our study (both institution based), the cutoff point to determine refractive error was set different (refractive error was considered $\geq 1.00 \mathrm{D}$, while $\geq 0.25 \mathrm{D}$ was considered as refractive error in this study).

The prevalence of hyperopia was $38.3 \%$ in the right eye (95\% CI: $37 \%-40 \%$ ) and $37.9 \%$ (95\% CI: $36 \%-40 \%$ ) in the left eye in this study, which is in line with a hospital-based study in Ghana (33.5\% hyperopia and $35.3 \%$ myopia) ${ }^{15}$ and Malaysia. ${ }^{16}$ However, the prevalence of hyperopia from this study appears lower than a cross-sectional study from Iran $(51.6 \%)^{1}$ and the north suburbs of Athens, Greece $(42.67 \%){ }^{3}$ These variations may be accounted for by the variation in the prevalence of refractive errors across different ethnic groups and targeted study population. This study also showed myopia in $34.6 \%$ of right eyes (95\% CI: $33 \%-36 \%$ ) and $34.5 \%$ (95\% CI: 33\%-36\%) of left eyes, which is higher than a report from similar study in Singapore $(34 \%) \cdot{ }^{17}$ However, it was lower than a finding from Greece $(57 \%)^{3}$ and Nigeria. ${ }^{13}$

Low-degree hyperopia (86\%) followed by moderatedegree $(9.5 \%)$ and high-degree hyperopia (4.5\%) were the most frequently observed myopias in this study. This was consistent with a report from Greece (low hypermetropia: 9.6\%, moderate: $3.27 \%$, and high: $1.53 \%){ }^{3}$ Similarly, lowdegree myopia ( $49.5 \%)$ followed by high-degree $(26.8 \%)$ and moderate-degree myopia (23.7\%) were the most frequently observed myopias in this study, which is also consistent with the study from Greece (low myopia: $28.60 \%$, moderate: 
$13.47 \%$, and high: $1.20 \%)^{3}$ except that high-degree myopia ranked second in the Greek study. High-degree myopia was also the most frequent refractive error in Japanese study $(38.9 \%) .{ }^{18}$ On the contrary, it was low in Asian patients with Down syndrome $(1.20 \%){ }^{19}$

The striking variation in the prevalence of refractive errors in males $(60 \%)$ and females $(40 \%)$ in this study was not statistically significant $\left(\chi^{2}=2.9, p=0.08\right)$, However, there is evidence that supports the variation between children and adults $\left(\chi^{2}=2.9, p<0.001\right)$. This was consistent with previous studies. ${ }^{17,20-23}$

The prevalence of refractive error in this study among children was $7.1 \%$. This result is consistent with the finding from Cairo, Egypt, $(7.1 \%)^{23}$ among school children, but higher than a study from Iran (4\%). ${ }^{24}$ This might be due to the variation in using the cutoff point for refractive error determination and the method of determining refractive errors. For example, in the Iranian study, refractive error was determined using cycloplegic autorefraction of myopia $(\mathrm{SE} \leq-0.50 \mathrm{D})$, while in the Egyptian study $+0.50 \mathrm{D}$ was the cutoff point.

The majority of powers prescribed were between +0.25 to $2.25 \mathrm{D}$ and -0.25 to $-2.25 \mathrm{D}$. This is instructive from the planning point of view for refractive error services. Stocking lenses in this range can serve the need of about $80 \%$ of the population.

\section{Conclusion}

This study has shown that refractive error is a common finding and the reason for presentation to the eye clinic in at Gondar University Tertiary Eye Care and Training Center. It has become essential and apparent that planning and stocking lenses with the appropriate lenses play an important role in addressing uncorrected refractive error.

\section{Acknowledgment}

The authors thank the University of Gondar for its financial support to conduct this study.

\section{Author contributions}

All authors made substantial contributions to conception and design, acquisition of data, or analysis and interpretation of data; took part in drafting the article or revising it critically for important intellectual content; gave final approval of the version to be published; and agree to be accountable for all aspects of the work.

\section{Disclosure}

The authors report no conflicts of interest in this work.

\section{References}

1. Abbas AY, Akbar F, Mehdi K, et al. The prevalence of refractive errors and its determinants in the elderly population of Mashhad, Iran. Ophthalmic Epidemiol. 2009;16(3):198-203.

2. Msiska V, Njuguna M, Kariuki M. Magnitude and pattern of significant refractive errors in primary school children of Lilongwe, an urban district in Malawi. East Afr J Ophthalmol. 2008;14(2):39-41.

3. Pateras E. Prevalence of refractive errors amongst adults, located at the north suburbs of Athens-Greece. Health Sci J. 2012;6(1):102-107.

4. Ayub A, Imran A, Saima A. Prevalence of undetected refractive errors among school children. Biomed. 2007;23:1-11.

5. Holden B. Blindness and poverty: a tragic combination. Clin Exp Optom. 2007;90:401-403.

6. Kovin SN, Jyoti J. Uncorrected refractive errors: community ophthalmology. Indian J Ophthalmol. 2012;60(5):432-437.

7. Serge R, Donatella P, Silvio PM, Gopal PP. Global magnitude of visual impairment caused by uncorrected refractive errors in 2004. Bull World Health Organ. 2008;86:63-70.

8. $\mathrm{Vu} \mathrm{H}$, Keeffe J, McCarty C, Taylor H. Impact of unilateral and bilateral vision loss on quality of life. Br J Ophthalmol. 2005;89:360-363.

9. Resnikoff S, Pascolini D, Mariotti S, Pokharel G. Global magnitude of visual impairment caused by uncorrected refractive errors in 2004 . Bull World Health Organ. 2008;86:63-70.

10. Haseeb MA, Irfanullah S, Jafri SI, Abdul SK, Syed IA, Mohammad J. Prevalence of refractive error in school children of Karachi. JPMA. 2008;58(6):322-325.

11. Smith T, Frick K, Holden B, Frickeb T, Naidoo K. Potential lost productivity resulting from the global burden of uncorrected refractive error. Bull World Health Organ. 2009;87:431-437.

12. Community Eye Health. Experiences with optical centres in West Africa. 2007;20:53.

13. Koroye-Egbe A, Ovenseri-Ogbomo G, Adio A. Refractive error status in Baylesa state, Nigeria. JNOV. 2010;16:11-14.

14. Yemane B, Alemayehu W, Abebeb B, et al. Prevalence and causes of blindness and low vision in Ethiopia. Ethiop J Health Dev. 2007;21(3): 204-210.

15. London School of Hygiene and Tropical Medicine. Refractive errors presenting to eye clinics in ghana: project report. Community Eye Health; 2007-2008.

16. Leon ES-MS, Pik-Pin G, Angela C, Anoop S, Donald TT, Leon E. Ethnicity-specific prevalence rates of refractive errors vary in Asian children in neighboring Malaysia and Singapore. Br J Ophthalmol. 2006;90(10):1230-1235.

17. Chen-Wei P, Ying-Feng Z, Ainur RA, et al. Prevalence of refractive errors in a multiethnic Asian population: the Singapore epidemiology of eye disease study. Invest Ophthalmol Vis Sci. 2013;54:2590-2598.

18. Sawada A, Tomidokoro A, Araie M, Iwase A, Yamamoto T. Refractive errors in an elderly Japanese population: the Tajimi study. Ophthalmology. 2008;115:363-370.

19. Kim U, Hwang J-M. Refractive errors and strabismus in Asian patients with Down syndrome. Eye. 2009;23:1560-1564.

20. Tan CS, Chan YH, Wong TY, et al. Prevalence and risk factors for refractive errors and ocular biometry parameters in an elderly Asian population: the Singapore longitudinal aging study (SLAS). Eye (Lond). 2011;25:1294-1301.

21. Hadi O, Akbar F, Hassan H, et al. Prevalence of the refractive errors by age and gender: the Mashhad eye study of Iran. Clin Experiment Ophthalmol. 2011;39(8):743-751.

22. Abuimara A, Tarshawi M. Prevalence of manifest hypermetropia in primary school children of Gaza city. Sci J Public Health. 2013;1(3): 131-134.

23. El-Moselhy EA, Abo-Seif HS , Abd ES, et al. Prevalence, risk assessment and impacts of eye diseases among school children in Cairo, Egypt. J Am Sci. 2011;7(1):235-246.

24. Farhad R, Mehdi K, Akbar F, et al. Prevalence study of refractive errors among school children aged 6-17 years in northeastern Iran. Ophthalmic Physiol Opt. 2012;32(1):25-30. 
Clinical Optometry is an international, peer-reviewed, open access journal publishing original research, basic science, clinical and epidemiologica studies, reviews and evaluations on clinical optometry. All aspects of patient care are addressed within the journal as well as the practice of optometry including economic and business analyses. Basic and clinica

Submit your manuscript here: https://www.dovepress.com/clinical-optometry-journal research papers are published that cover all aspects of optics, refraction and its application to the theory and practice of optometry. The manuscript management system is completely online and includes a very quick and fair peer-review system, which is all easy to use. Visit http://www.dovepress. com/testimonials.php to read real quotes from published authors. 